\title{
Developing and teaching of a world-class online project management curriculum
}

Stephen A. Leybourne, Vijay Kanabar and Roger Warburton

Metropolitan College, Boston University

\begin{abstract}
The evolution of the internet and collaboration tools have made it possible to enhance the range of online education, and make it universally accessible and eminently affordable. Around 2000, the faculty at Boston University's Metropolitan College proposed an online master's degree in project management, using the emerging learning management systems. The program grew quickly from 40 to 200 students, and was one of the first in the United States to be accredited by the Project Management Institute's Global Accreditation Committee. This academic model has now been extended to other disciplines and programs.

It was expected from the outset that the BU online and classroom academic experiences would be completely equivalent. This presented several challenges, the first of which was developing online equivalents for the face-to-face pedagogical course components. Second, writing online courses, recording videos and developing innovative discussion topics is time-consuming, and we quickly realised that only fulltime faculty had the commitment and motivation to devote the required effort to produce quality courses. Finally, the technological resources associated with course development and course operation required significant investment, beyond the faculty time, currently estimated at around $\$ 60,000$ per course.
\end{abstract}

We surveyed our students and alumni every two years and now have enough data to describe accurately the evolution in attitudes to online education.

As one of the earlier and premier adopters of a rigorous academic online education model, BU has a vested interest to contribute to the growing debate about the academic quality and rigour of online education, the application of high pedagogical standards, and the innovative use of online teaching frameworks and tools. This paper will address and document these issues and assist in raising awareness of emerging "best practice" in the online education domain. 


\section{Introduction}

It is generally accepted that project management (PM) is emerging from the wilderness of unrecognised and neglected management theory into an area where many practitioners are using project-based activities as the accepted way of implementing organisational and strategic change (Cicmil \& Hodgeson 2006). Many companies are beginning to accept management by projects as the framework within which organisational development is embedded. As a result, employee and managerial knowledge of PM is prized, and employers see proven PM as an important component of the skill set of the modern manager.

This desire for managers with PM skills has increased the demand for courses, in both number and scope, that profess to offer a grounding in those skills, and especially for some form of accredited diploma or certificate to document the skills. This trend has been exacerbated by several factors: PM is a new academic discipline and academic degrees are rare, and often departmental orphans. The Project Management Institute (PMI), has attempted to fill this academic accreditation vacuum in the United States with their Global Accreditation Center (GAC).

In the international arena, there has also been a rise in influence of professional organisations that tout PM as a management panacea, e.g., the United Kingdom Association for Project Management (APM) and the Australian Institute of Project Management (AIPM). Many of these professional associations offer so-called "accredited PM" qualifications.

Despite the fact that these accreditations are professional and not academically based, many educational institutions have chosen to follow the standards set by these associations. Even a cursory review of academic course catalogues shows that there is significant variation in the quality, scope and credibility of academic courses. There is also considerable variation in the mode of delivery of such courses and, in particular, the growth of online delivery has extended the reach of institutions by providing new, different and innovative ways of reaching, communicating with and assessing the student market for PM education.

PM credentials are often sought by working professionals as an add-on to their technical specialty. The Boston University (BU) survey showed that $89 \%$ of students were employed fulltime. The professional associations have been successful in communicating the idea that PM is applicable across many professions, which has created a huge market for graduate professional education. In the absence of degrees in PM, many government and commercial organisations have started demanding "certification" of both their own and externally subcontracted project managers.

One of the touted benefits of the rise in online education is that PM practitioners can study in a more flexible and asynchronous way, while continuing to meet the demands of their daily lives, families and even fulltime employment. This is eminently compatible with the idea of graduate professional education and has opened up the opportunity for many to engage in "lifelong learning" initiatives. Students keep their professional skills up to date by combining a mix of academically delivered courses with experiential knowledge generated in the workplace. 
The idea of graduate professional education is also underscored by the age profile of the BU students, which is shown in Figure 1.

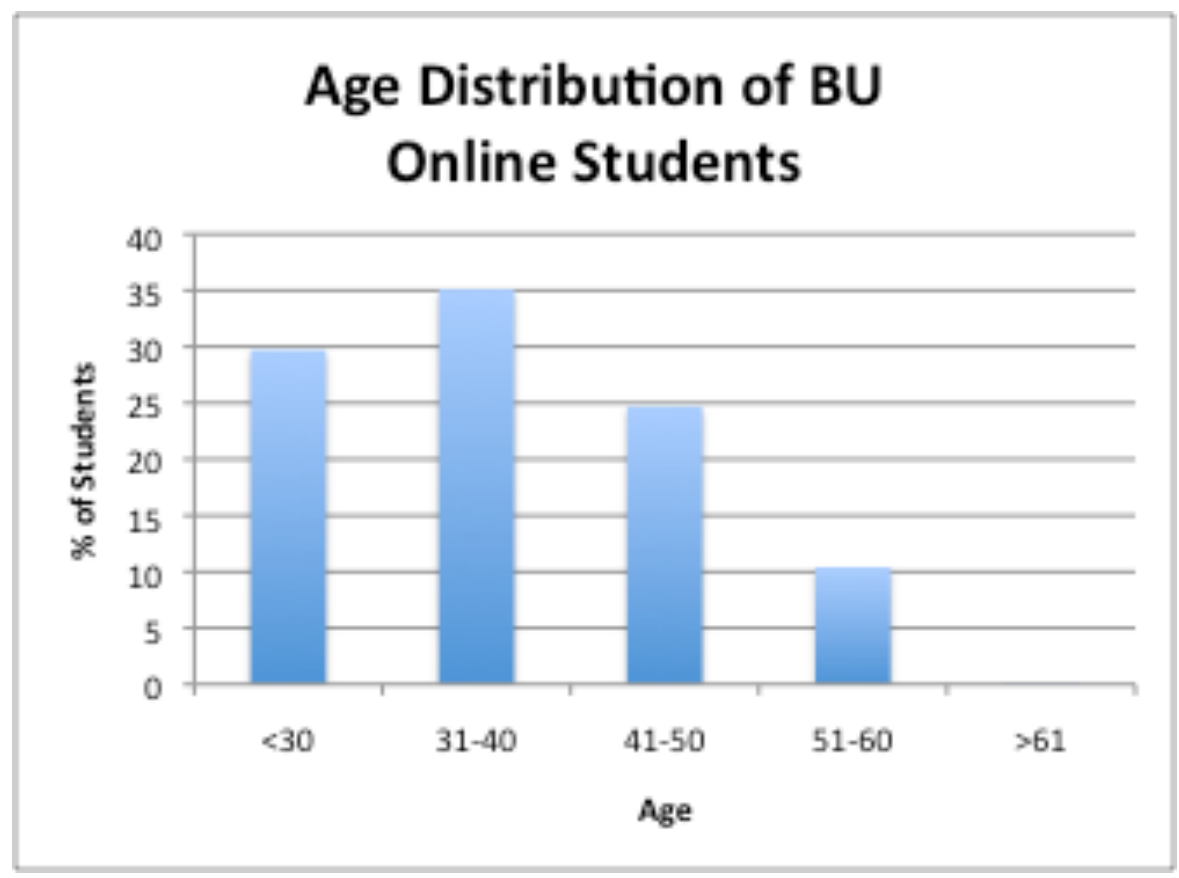

Figure 1. The age profile of $\mathrm{BU}$ online students

This innovative mix of the academic and experiential is increasingly seen as valuable to both the stakeholders involved: the companies paying the bills, and the students taking the courses. At least in the US, companies contribute significantly to their employees' professional development. In fact, the Dean of BU's Metropolitan College, Jay Halfond, often says that the College would not exist without the investment by companies in their employees' education. (Students report that $30 \%$ of the tuition comes from their employers, 30\% from savings and 30\% from loans.)

Hard-nosed business executives must be convinced that graduate professional education is an effective way to enhance the skills of their employees. Only then are they willing to invest directly in the education of their employees. On the other hand, it appears that students (i.e., employees) have a completely different motive for pursuing their education. While companies are motivated by the practical desire to acquire better-trained employees, students are motivated much more by self-fulfillment. When asked why they pursued a degree, students usually express the desire of increasing their knowledge base to compete with their peers. In our experience, they rarely seek a graduate degree in a specific discipline (i.e., PM) solely to get a better job.

We have been consistently surprised by the students' expression of their motivation for pursuing a degree. While obtaining a degree is important (90\% said it was very important), they suggested that the following were also very important: Personal satisfaction (74\%); Improving job skills $(63 \%)$; and Learning a new field (55\%). We emphasise that these personal development ideas were touted as very important, not just important. In fact, only $21 \%$ took the course to meet job requirements, and only $7 \%$ upon recommendation from their employer. 
This difference in educational goals between students and companies significantly affects the marketing of the PM programs. Marketing to companies must be practically oriented, stressing the value of the education as a return on investment, and expressing the idea that the programs provide employee skills that are of immediate benefit to the company. Ironically, companies see a long-term degree program as a good idea, in that it binds employees for the term of their degree. We see our obligations to the employer as delivering skills and knowledge that can be quickly and effectively employed for organisational benefit.

Marketing to students, on the other hand, is aimed more at self-fulfillment, career progression (which we recognise and acknowledge as a driving force, even if many of our students don't), and engagement with the lifelong learning agenda that has become the accepted paradigm for the realization of organisational ambition.

This paper documents the way in which one leading, traditional university - BU in the US has engaged with this emerging "online" model to deliver high-quality PM education at the graduate level.

\section{Defining quality in online education}

Online education is an emotive subject, and one where there is much public debate about both the quality of the educational programs, and the processes that are used to design and deliver them. It has been suggested that the delivery of higher education courses online "holds greater promise and is subject to more suspicion than any other instructional mode in the 21 st century" (Casey 2008: 45). Much of this suspicion revolves around the concept of academic quality, a concept to which traditional classroom measures can be difficult to apply in the online arena.

Shelton and Saltsman (2004) have suggested that indications of quality for an online education program are not linked to its growth rate (i.e., a business metric!), but to a combination of retention rate, academic outcomes, post-academic success of the online student and faculty support. Strangely, this view of quality does not mention academic rigour or pedagogical standards, which are arguably the most important traditional arbiters of academic quality.

Recently, Saltsman (2011) has identified 13 paradigms (although whether they are all true paradigms is debatable) that can potentially be used to assist in the assessment of online program quality. One of the most recognised of these is the Sloan Consortium framework, with its "five pillars" of quality (Sloan Consortium 2009). These pillars, which the Consortium considers to be essential to quality online learning, are: learning effectiveness, student satisfaction, faculty satisfaction, scale and access.

One might argue that learning effectiveness is the only pillar with a pedagogical basis. Student and faculty satisfaction, although nice to have, are not academic goals for a course. Scale and access are concepts associated with fairness and availability which, again, are not pedagogical goals.

In fact, when creating online courses, our primary goal was to make them as indistinguishable as possible in all respects from their classroom equivalents. We started by making the curricula 
identical, in lectures, homework assignments and, especially, the final research report. These goals look nothing like the Sloan pillars. However, this "equivalence goal" was essential in communicating to a sceptical administration that we could create and deliver a quality academic degree program online.

There are a number of other models or frameworks documented in Saltsman (2011), which is essentially a review of the various studies to date in this area. It is not surprising that they contain common themes and outcomes, the strongest being the importance of institutional commitment, support and leadership. At BU, we were fortunate that both academic and administrative hierarchies were committed to, and supportive of, online education.

Table 1: Adapted from Chaney et al (2009)

\begin{tabular}{|c|c|}
\hline Theme & Indicator \\
\hline $\begin{array}{l}\text { Teaching and Learning } \\
\text { Effectiveness }\end{array}$ & $\begin{array}{l}\text { - } \text { student-teacher interaction } \\
\text { - } \quad \text { respect diverse ways of learning }\end{array}$ \\
\hline Student Support & $\begin{array}{l}\text { - } \quad \text { student support services } \\
\text { - clear analysis of audience }\end{array}$ \\
\hline Technology & $\begin{array}{l}\text { - technology plan to ensure quality is documented } \\
\text { - } \text { appropriate tools and media } \\
\text { - reliability of technology }\end{array}$ \\
\hline $\begin{array}{l}\text { Course Development \& } \\
\text { Instructional Design }\end{array}$ & $\begin{array}{l}\text { - } \text { course structure guidelines } \\
\text { - } \text { active learning techniques } \\
\text { - develementation of guidelines for course } \\
\text { dinent/review of instructional materials }\end{array}$ \\
\hline Faculty Support & - faculty support services \\
\hline Evaluation and Assessment & - program evaluation and assessment \\
\hline $\begin{array}{l}\text { Organizational \& Institutional } \\
\text { Impact }\end{array}$ & $\begin{array}{l}\text { - institutional support and institutional resources } \\
\text { - strong rationale for distance education/correlates to } \\
\text { institutional mission }\end{array}$ \\
\hline
\end{tabular}

Chaney et al (2009) developed a set of common quality indicators from their review of the domain, which are documented in Table 1 . The above quality indicators can be roughly grouped as follows:

- Faculty-student interaction

- Infrastructure investment (technology, tools, student services, etc.)

- Faculty development (training, support, guidelines, etc.)

Of these, we find that the first (faculty-student interaction) is by far the most important factor in student satisfaction, and this is strongly supported by survey data (Zlateva 2011). The BU survey data echoes this strongly. Only $63 \%$ of students are either satisfied or very satisfied with the "availability of faculty" and, for us, this represents a definite area for improvement.

When asked "What would they like to see more of?" the consistent comment was "more interactions with faculty". This was repeated in many forms: more faculty interaction with 
students on message boards; more faculty live synchronous sessions; more faculty participation in discussions; faculty being present and interacting more; and faculty offering online chats. One cannot mistake the dominance of the word "faculty" in all the above comments.

In the early days, we had to battle the hysteria that "online education was different". The following view was typical: "For modern educators, however, the teaching paradigm of "sage on the stage' has transformed to a 'guide on the side'." We slowly rejected these ideas, as it became obvious that more "teaching" led to better student interactions in discussions, more learning by the students and even more satisfaction as reported by the students themselves. We were discovering that what dominated student acceptance in the online arena was, in fact, more faculty interactions. Fortunately, the technology has improved markedly in the past couple of years. Fast internet connections are now ubiquitous, and faculty can hold live chats sessions (video sessions are becoming popular) without leaving anyone out.

Interestingly, $74 \%$ of students were either satisfied or very satisfied with the "quality and availability of student-to-student collaborations". They seem to be happy with their interactions with each other, just not so much with the faculty. This suggests that it is not a technological issue because if it were, one would expect students to complain about both types of interactions. In the online environment, faculty must face the fact that they need to work harder on their interactions with students, employing multiple modes in diverse ways.

Another key element in Table 1 is the importance of investing in course development. Fortunately, the faculty at BU is supported in the development and delivery of courses by firstclass technology. The university has invested heavily in an Office of Distance Education, with the skills and expertise to implement faculty-designed courses; maintain the technological infrastructure; and educate faculty in the latest technological developments. The Office of Distance Education is financially supported by a modest technology fee of $\$ 50$ per credit hour.

We have repeatedly learnt that a fulltime faculty is required to run programs effectively. We have also learnt that only fulltime faculty members are capable of developing credible academic programs. They have the resources, time, commitment and expertise, both academic and pedagogical, to develop and monitor the curriculum, provide student advising beyond the course level and generally ensure the ongoing quality of the program.

Adjunct faculty members are an essential and critical resource in the teaching of online courses but do not have the background and perspective to monitor and control a complex, multicourse program. Several of our biggest failures were the result of placing adjuncts in roles for which they were not suited. Most adjuncts have jobs and the monumental time commitment required to develop online courses is frequently beyond them. Even though they are paid for it, many adjuncts have started an online course development only to abandon it in the middle as being too much work. This is not a criticism of the work of adjuncts; we accept full responsibility for asking them to do a job that we now regard as impossible.

Although we have been successful in using some adjuncts as administrators, we have also found that we need true academic professionals familiar with PM research to effectively monitor and, especially, develop the curriculum. We now regard research qualifications as the most important 
faculty qualification, and these distinguish the pre-eminent "academic" institutions that are dedicated to the provision of rigorous, pedagogically sound, offerings from the less credible programs that could undermine the integrity of online PM education.

\section{Pedagogy in online PM courses}

One thing is clear in any debate about quality in the delivery of online education: the application and maintenance of pedagogical standards is of paramount importance.

Pedagogy is often defined as the art or science of being a teacher, although a wider view considers "strategies of instruction", in that there are many ways to teach, and many strategies may not be appropriate in certain situations. Online education is significantly different in its modes of delivery from classroom-based teaching, and it is therefore vital that we reflect on the pedagogy that is at the core of what we, as online educators, are trying to deliver.

We are building communities of learners and, in a truly collaborative environment, both teachers and students are learning constantly (Phillips et al 2008). The learning environment therefore needs to be flexible and adaptable, so that it can quickly respond to the needs of the participants within it, and meet the requirements of students, instructors, the learning materials, and the collaboration requirements and assessment requirements embedded in the course design. (McLaughlin \& Lee 2008).

One of the key ideas that students immediately communicate about the online environment is that they learn by different methods. (This is undoubtedly also true in the classroom, but perhaps so obvious there that students do not feel the need mention it.) However, the online student is immediately faced with a barrage of different media (or "learning objects" in the jargon of the trade). The combination of text-based lectures, short videos, discussion groups, emails and faculty discussions force the student to assess which aspects they respond to best.

Online students speak up immediately. We do not know whether this is because they are a different demographic from classroom students, or whether the online environment provides an anonymity that encourages speaking out, or even if the online pedagogy truly has a different impact on the student.

Therefore, we have evolved to provide the same pedagogical idea from multiple perspectives. Fortunately, in the online environment, this is where the technology assists in providing several formats, e.g., lectures and videos, with concepts reinforced in discussions and homework. As teachers, we probably do this without giving it much thought in the classroom when we cover a concept from several different perspectives and when we throw the topic out for wider discussion.

Online, the different modes of communication must be explicitly included. It is not enough to write a lecture and simply tell the students to read it. By covering a topic with a lecture, video, and discussion, it may appear that one is duplicating information with boring repetition. In reality, one is providing many different ways of communicating the desired concept. In the online environment, therefore, it takes a significant investment of time, and some creativity, to find effective ways to present the same information in different forms. 
This leads to the topic of innovation in curriculum design and, specifically, balancing the effective delivery of appropriate materials with the need to measure student needs and expectations. These issues will be dealt with later in the body of the paper, as we talk specifically about the experience of teaching a BU online PM program.

\section{The Boston University legacy in online education}

BU has been offering PM courses on campus for more than three decades. Prior to the arrival of the internet, online courses were delivered via satellite and PictureTel videoconferencing to remote classrooms or corporate sites. Beginning in 1998, BU invested in web-enabled platforms for course delivery, but the subsequent introduction of learning management systems, such as Blackboard and Vista, allowed us to investigate the implementation of distance education.

In September 2005, we offered our first Master of Science in Project Management (MS PM) online, using a locally hosted version of Vista. The first class consisted of 40 students, which rapidly increased over the next three years. We now have a stable enrolment of 200 students each year in the PM program - roughly 150 in the MS PM and 50 in the Master of Science in the Information Technology Project Management (IT PM) specialisation.

The fulltime faculty that teach in our PM program are all active researchers, and involved in the expansion and dissemination of the growing literature in the PM domain. The BU faculty publish and present their findings to academics and practitioners, and are connected to academic and practitioner networks. The relation with the practitioner community through user groups, PMI Chapters, and special interest groups (SIG) is unique to PM, and often leads to joint publications, and the growth and sharing of the PM knowledge base.

The BU PM faculty are also represented on the editorial boards of PM journals and on PMI committees. We believe that this connection between the generation of knowledge and its wider dissemination — both within our PM program and more widely — is what makes the difference between a competent program and a world-class one.

\section{Supporting excellence in project management student research}

To support excellence in PM education and, especially, to nurture student research in the discipline, we organise an annual research conference in May. The conference features faculty and student presentations, and is marked by papers and panels that centre on a core theme.

The student papers combine their practical work experience with issues they have studied in their PM degree curriculum. Since a majority of our students are working professionals, the conference provides an opportunity for students to take their education to the next level by integrating their real-world PM experience with current research. A wide call for papers to all students is announced throughout the academic year especially in the PM courses. A small committee evaluates student papers for academic rigour, and only about a third of the submissions are selected for presentations. The proceedings are published, with an ISBN.

The annual conference brings dozens of online students to campus, providing them the opportunity to interact with professors and sharpen their research skills. But what is most 
encouraging is that so many students want to participate in the conference (as a presenter), and learn research methods from the professors, fellow students and practitioners.

The feedback shows that students appreciate the opportunity to visit Boston and to present at the conference. For most of our online students, however, it is a financial burden to visit Boston. Therefore, to encourage even wider participation, in 2011 we evolved to an online conference format. We closed registration after more than the authorised 150 students had registered. From the positive evaluations we have received, we believe we have successfully tested this new paradigm that allows wider participation in our research conference, and plan to use this mode to encourage even more student papers at a distance. Again, we see the importance of the critical role of experienced and "connected" fulltime faculty, without whom such a conference would not be possible.

\section{The Boston University PM online experience}

The BU structure

It is worth noting that the BU model is unique. Course enrolments in the PM classes may exceed 150 students. If that occurs, the course is divided so that each class has around 75-90 students. Each class has its own faculty member and, in the case of the PM courses, most are fulltime members of the department. In the 2010-2011 academic year, fulltime faculty taught six of the eight PM courses. The remaining two classes were taught by an experienced adjunct with a PhD.

Each class is divided into sections, of 12-15 students, each with its own Teaching Assistant, or Facilitator. Facilitators are responsible for the grading of discussions, homework assignments, and research papers. Facilitators are also the first line of support for questions from the students. Each week, a telephone conference is held by the faculty member with all the facilitators to discuss the previous week's issues and expectations for the upcoming week. All facilitators have masters degrees, and are PMP $^{\circledR}$ certified.

Facilitators also monitor the discussion forums, guiding and encouraging the students toward the right goal. A subtle balance must be maintained between getting the students to the right place, and not giving away the answer.

Large classes also have a Facilitator-at-Large (FAL). It was realized early on that large online classes result in a lot of non-academic bookkeeping and handholding of the students. When the faculty was responsible for this, there was little time left for teaching. As a result, we introduced the idea of the FAL, whose job it is to be the assistant to the faculty member and take care of the administrative details.

The FAL is typically a very experienced facilitator, with whom the faculty member feels comfortable asking to review student questions and issues. The faculty member in charge of the course and the FAL have usually evolved a common understanding, and share a philosophy about sensitive topics, such as students missing assignments, complaints over grades, etc.

The typical flow of a student issue is as follows: the student writes to the faculty member with a problem. If appropriate, the faculty member can delegate it to the FAL, who drafts a response to the student and sends it to the faculty member. The faculty member finetunes the response and 
replies to the student. This has the advantage of keeping the faculty member responsible for all issues, but without the responsibility of standardised bookkeeping. Many issues can be dealt with routinely by the FAL (e.g., sickness, work or family issues)

Grading is a major topic of discussion between faculty and facilitators. First, faculty set expectations and clearly define the grading criteria. Just as in the classroom, the clearer the grading criteria, the less likely there are to be issues when the students receive their grades. One problem with large classes, which is not unique to online, is the maintenance of a common grading standard across sections.

The FAL plays an important role in maintaining consistent grading standards. FALs monitor the grading across sections, selecting some good and some poor homework assignments to check grading. They also prepare weekly histograms of grades by section, so that grading consistency can be maintained. New facilitators invariably grade too less strictly, and it takes a course or two for them to figure out the BU quality criteria. Like students, facilitators also have fulltime jobs, so when facilitators need to travel for a few days, the FALs act in their place.

\section{Designing a course}

When designing a course, faculty initially go through a predictable cycle. The first contribution is usually rather textbook oriented. Students react negatively to this, and wonder (often out loud!) what is the point of the lectures if they simply follow the book. Faculty then begin to ask themselves "What is it that the students need to learn?" In our experience, it is at this point that an interesting online curriculum begins to emerge. It is also at this point that a curriculum coordinator is essential as, otherwise, faculty may include material that overlaps with other courses, is not relevant, or is less important than the established syllabus topics.

\section{The maths videos (Pocket Tutorials)}

An interesting phenomenon has emerged surrounding the inclusion of short videos. Short videos were originally required as many of our students were restricted to dial-up internet connections. Faculty members were therefore encouraged to develop many short videos, rather than record long lectures.

This had an unintended, but marvelous consequence. Recognising that PM students tend to struggle with mathematics, we began recoding many short videos on topics such as net present value, earned value, etc. We gradually realised that students watched these over and over again. Short videos allowed the students to study the piece that they did not understand at their own pace, and as many times as they needed to.

This also reinforced the idea that different students learn, not only at different rates, but from different media. BU is fortunate in that the Office of Distance Education provides professional videographers and editors, so the videos are of excellent quality.

The dial-up requirement has long since gone, but the short video remains as a premier communication tool. The videos are not a substitute for other modes such as lectures, discussions, etc. They are a complement. 


\section{Online discussions}

One of the challenges in online education is the discussion forums. Early on, many faculty used discussions as a kind of weekly review of materials. Graduate students quickly seized upon this as make-work and objected loudly.

We therefore set about defining interesting discussion topics, a task that is quite difficult. In the best classes, online discussions have an arc, just as a TV series does for the season, although without the cliff-hanger. We are becoming convinced that in an online class, discussions are where teaching happens.

Discussions must be actively controlled, which at first seems counterintuitive. The modern student's approach to a discussion is often like that of a blog, and they throw anything up there. The job of the first week, especially in a first course, is to educate the students about what a discussion is. One way to accomplish this is through more videos, which immediately gives videos a much more diverse role than just content presentation.

For example, in the first PM course, which for most students is also their first online course and their first graduate course, the first assignment is to comment on the role of the project manager, as described in the lectures, or by the PMI. Many students throw up unsubstantiated opinions and off-hand comments, despite the fact that there is a video clearly explaining that, among other things, references are required and opinions need to be backed up.

At the beginning of the second week, another video is released to the students, and chastened by poor grades, they begin to pay attention. The new video explains how the previous week's assignment might have been done. This video is a recording of a session in which the faculty member goes to the "library" (digital, of course), searches for research articles on topics mentioned in the lectures, explains how to evaluate abstracts, and shows how to cite and reference correctly.

The second week's discussion must thus give the students something meaningful to research, as they are primed and set up to do just that. It is in this sense that the discussions have an arc. Each has a reason for inclusion; they cannot be a random collection of disjointed topics.

Students need training in posting to discussions and it takes several weeks for them to get the hang of it. After the admonishments about references and backing up of opinions, they often overreact by posting essays. This must also be discouraged, as the goal is for a discussion to happen. To foster a discussion, students must also be encouraged to respond to other students' work. The grading rubric can help here, where it can be made clear that interaction is a necessary requirement for a good grade.

Interestingly, it is here that one of the most powerful antecedent benefits of online study becomes apparent. "Experienced" students, who may have completed much of their program, are hugely supportive of "newer" students, offering advice, tips, help with navigation of the technology platform, assistance with the difficulties of dealing with compatibility issues (we have a very high incidence of Mac users) and other useful help. This has become a powerful advantage and we now deliberately build structures into the course that allow this tutoring activity to flourish. 


\section{Excellence in online communication}

In this section, we describe the communication that takes place between faculty and students and among students (Figure 2).

\section{Any Time Same Time Same Place $\quad$ Same Place and \\ Communication \\ 3
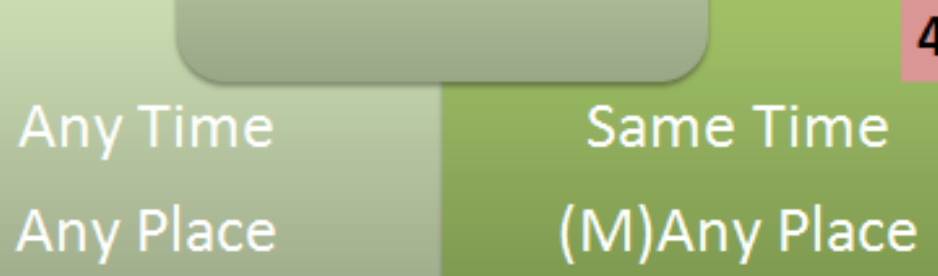

Figure 2. Communication framework: communicating with students face to face

The MS PM program was designed from the outset to be entirely any time, any place.

(Warburton, Leybourne \& Kanabar 2011). Figure 2 shows a representation of this idea. Any time, any place is diametrically opposite to traditional classroom teaching, which is same time, same place - see Quadrant 2. The anytime, anyplace framework was essential because most of our students were not locals. In fact, we have many military students serving in Afghanistan, Iraq and in the demilitarised zone in Korea. We even have students serving on ships at sea or at some undisclosed location.

Only $40 \%$ of students are from the Northeast, with $85 \%$ of students living more than $160 \mathrm{~km}$ miles from Boston and scattered throughout the US; 7\% are international and 5\% in the military.

Students access our courses at any time. We frequently notice 40 students online at midnight Boston (EST) time. Of course, most of these students are in the Pacific Time Zone. The courses were all designed for the any time, any place model. Early on, we imposed the idea that there could be no synchronous communications, because of the time zone differences.

Two years after the program began, we reacted to the constant drumbeat of interest from students desiring some synchronous online interaction with faculty members. We identify this as "same time, any place" - see Quadrant 1 in Figure 2. There is emerging empirical support for this in other institutions (McBrien, Cheng \& Jones 2009). 
As indicated in the survey and reported above, students wish to communicate with faculty in a live dialogue, not just in a discussion forum and, for working students, the weekend is usually preferred. To satisfy this demand, the Office of Distance Education introduced new tools to facilitate live lectures and meetings. The default tools provide free access, and these are Wimba and Pronto. Once again, we see the importance of the commitment of BU to the online program. However, faculty are free to use any tool or technique they prefer, e.g., Gotomeeting and Skype were used by some faculty and facilitators as early as 2007 .

Staying with the spirit of our core mission of any time, any place, we did not mandate student attendance at such meetings, but did record all live sessions and interactions with students. Students whose learning style was enhanced by live chat benefitted tremendously from this model of live weekly communication.

Interestingly, a review of attendance metrics data revealed that many students who missed the live interaction, and even some who attended the live meetings, viewed the recordings. Especially as the course proceeded, and the topics became more complex, more students reviewed the live chat sessions. The earned value chat session is exceeded in attendance only by the final exam review!

Initially, the attendance at most live lectures rarely exceeded $40 \%$ of the class, which we put down to time zone issues, family and work constraints. Also, no matter what time a live chat is scheduled, it is always 3 am for some students, somewhere!

The demand for more chat sessions is interesting in that the amount of time students devote to their studies is already substantial (23\% of students spend less than 15 hours per week; $37 \%$ spend 15-20 hours per week; while the remaining 40\% spend $>20$ hours per week.).

In our experience, students use the live chat opportunities not only to learn from the faculty member, but also to chat synchronously with fellow students. They share information about the class, homework, useful URLs and even the weather. The online chat sessions are livelier and more informal that their classroom equivalents.

Student evaluations have revealed considerable satisfaction with the effort put in by faculty members who reach out to students in a synchronous manner. While it adds to the faculty's work load, it certainly results in better quality communications with the students. We regard this extra effort as a worthwhile investment that supports excellence in online PM education.

Recently, we have noticed that the number of students attending the live chat sessions is gradually rising. We are not sure of the exact reason, but contributing factors include the students' increasing familiarity with the idea of video chats; the availability of cheap web cameras; and reliable bandwidth.

Since 2008, we have reached out to our PM students using the same time, (m)any places model see Quadrant 4 in Figure 2. The idea was to: a) reach out to students at a place close to them; and b) gather students at a place of learning. 
Our first effort was to reach out to students in a single geographic region was in Atlanta at the PMI Global Congress in 2007. We organised two events to communicate with our online students and alumni. The first was a PMP ${ }^{\circledR}$ Preparation workshop for BU students and alumni, which was held on 12 October 2007. Several online students and alumni took the opportunity to meet with faculty (and the Dean), who were presenting research papers at the conference. The students were delighted to meet the faculty face to face for the first time. In the following years, this experience was repeated at the PMI Congresses in Denver, Seattle and Washington, DC, and is scheduled to be repeated in Dallas in 2011.

We have been pleasantly surprised by the students' sincere appreciation of all such efforts to communicate with them.

\section{Proctored exams}

When we started the MS PM online program, the faculty unanimously decided to enforce the idea that all courses must have a proctored final examination. This was not common practice at the time, and the Office of Distance Education was at a loss as to how to implement the proctoring of exams for students all over the world.

We were determined to find a solution, and for very good reasons: we wanted to ensure that the student in the course was indeed the student taking the exam; in other words, that the student was legitimate. Proctoring ensures such a validation as the student has to present a photo ID (such as a university ID, passport, or driver's licence) at the examination centre. Also, if the exams are closed book, the proctoring centre ensures that the student brings in no materials.

Initially, most students took their proctored exams at standardised test centres. In special circumstances (e.g., military students overseas), we also allowed students to designate someone responsible (e.g., a senior military officer) as their proctor. The Office of Distance Education now has a dedicated staff member to help with finding proctoring centres and validating individual proctors.

A new product called Procter Cam has emerged, which makes proctoring so much more convenient for everyone. By all accounts, Proctor Cam is a success and is working well. Proctor Cam allows the student to take the exam at their own computer, monitored by their own web camera. Proctoring is handled remotely by a live proctor: the student pans the camera around to ensure the exam conditions are proper; during the exam, the proctor monitors the student's desk and room to ensure no one comes in or talks to the student.

Within a year of its introduction, Proctor Cam has become the method of choice for the majority of students. The cost of proctoring is substantial, more than $\$ 50$ per student. However, this investment in proctoring, which is borne by the university not the students, is clearly correlated with quality, and this is evident even to students. We recall a memorable interaction in a water cooler discussion. A student was lamenting the trouble that he had to go through ... driving to a proctoring centre and taking the exam. Another student remarked, "I'm in favour of going through this small inconvenience. I joined BU PM because of its reputation - that it does not give out degrees without ensuring integrity". 
The issue of institutional integrity comes up frequently in discussions, and the conclusions are supported by the survey data. While $34 \%$ of students said they selected an online program because of the time convenience, another $34 \%$ said that the institution and program being offered was more important, with another 19\% selecting the institution just for its name.

In selecting a university, $82 \%$ of students say that the "reputation of the institution" is very important (another 16\% say it is important), and $86 \%$ say that the "quality of the overall academic instruction" is very important.

\section{Quality via Turnitin}

BU makes available to all faculty, at no cost, a product called Turnitin. If students plagiarise, this product catches them: it documents precisely where sentences or phrases were copied from. Faculty who suspect cheating can submit the work to Turnitin, and quickly receive a report on the degree to which the student copied the paper.

Since we teach graduate students, this is a rare occurrence. But when we need it, we really need it. Fortunately, the report form Turnitin is so thorough, that when students are presented with their plagiarised work, there is little debate, and a stern warning usually suffices. For significant plagiarism, students are reported to a disciplinary committee, which, historically, is quite severe in its punishment.

\section{Limiting the number of " $A$ " grades}

We encourage students to produce outstanding work. We set challenging homework and discussion assignments, and demand that students aim to produce original, publishable quality work. Only the best work receives an " $A$ " grade. This is not a policy that is special to the online PM program, but a general standard set by BU. The result is that the total number of $\mathrm{A}$ and $\mathrm{A}-$ grades is about $20 \%$ of the class.

\section{The issue of teaching cases online}

In this section, we briefly discuss an outstanding pedagogical issue associated with online classes, with which most faculty seem to have a real problem - the teaching of cases.

Over the past two years, and after much discussion, we have put significant effort into the teaching of cases online. We now have an "innovation" class running online, which is taught using the Socratic method, with rigorous case studies forming the basis of the week's discussions. This course has run successfully three times, and faculty are now developing an entrepreneurship course that will use the same case-based Socratic model. So far, reaction from students has been very positive, and our efforts to make this work online has also opened up the opportunity for other disciplines (e.g., law and medicine) to adopt this model.

The Socratic Method is based on "learning by asking", rather than "learning by telling". It is a dialectical method, rooted in dialogue, and often involves adversarial discussion, in which the defence of one point of view is pitted against that of another. One participant may lead another to contradict himself or herself in some way, thus strengthening their own point. 
We have, however, deliberately avoided suggestions that discussion postings are required to "rebut" previous contributions; rather, they are expected to contribute to deeper analysis and discussion. The goal is that by being asked questions students are driven to apply general concepts to specific situations; to argue their analysis to others; and to critically test this application in the cauldron of intense group interaction. In so doing, students learn to apply theory and definitions, rather than just describing them.

Through discussion emerges a series of "agreed upon" applications of complex concepts, a better understanding of the real meaning and detail of those concepts and how they should be applied, and an integration into practice and decision making of additional research findings from the wider literature. This use of the Socratic Method is a perfect example of our insistence on maintaining, indeed reinforcing, the pedagogical rigour of our online offerings.

\section{Conclusion}

We are often asked to compare online and classroom teaching. Table 2 summarises the issues with online and classroom students in several dimensions (Warburton et al 2011). 
Table 2. A comparison of online and classroom students

$\begin{array}{ll}\text { Research papers } & \text { Equivalent } \\ & \text { Each PM course ends with the requirement that the student write a } \\ & \text { research paper. If you were to place a pile of online papers next to a pile } \\ & \text { of classroom papers, you would not be able to tell which was which. } \\ & \text { The students end up at the same place. }\end{array}$

Discussions Online students are much better at discussions. This may be because we force them to approach the discussion in a more formal and academic way. We require references, in APA style.

Classroom students are used to just showing up with a few notes, but they are used to engaging interactively.

Independence Online students are much more independent. You tell them to read a lecture, and they do. Online students may be self-selected to be more independent.

Classroom students want to be led through the material.

\section{Creativity}

Classroom students are more creative in their responses. This may be because of the group dynamics in the classroom. It is easier for colocated students with a physical relationship to work through team phases, to engage with team roles and to interact than for "virtual" team members.

However, notwithstanding this, we are constantly amazed by the virtual skills of our Online students.

\section{Group projects}

\section{We do not know enough about how to do these effectively online.}

There are lots of technologies (Wikis, etc.) but just because the technology is there, does not mean it actually accomplishes a group project.

Technology also gets in the way and defines the format of the response. Something that does not happen in the classroom, which is much more free-form.

Faculty who teach online almost always remark that it is a lot of work. The question of whether it is more work than classroom teaching is open to debate. Classroom and teaching styles vary so much that it would be a difficult to question to answer statistically. However, a number of points are clear.

For some arcane reason, most online courses are accelerated. For example, at BU the online course is seven weeks, while classroom courses are 14 weeks. Since online and classroom curricula are identical, the interesting question is whether an online course is more than twice the work in half the time of a classroom course.

A second aspect of the online schedule is that it is relentless. The next week's classes begin on Tuesday, no exceptions. Therefore, any homework questions have to be answered on Sunday or 
Monday. In a classroom situation, a teacher can postpone a topic to the next week, or even delete it. Not so online.

We have come to appreciate online teaching, but regard it as a completely different animal from classroom teaching. In general, we have found that good techniques in the classroom work online. The cases that seem to work well in the classroom, work well online. Often, the approach by the faculty member must be different, but all students seem to get to the desired place.

The opposite is also true. Disorganised assignments or lectures confuse both classroom and online students. Unclear grading standards drive all students crazy. It is therefore essential for both classroom and online programs that pedagogical imperatives are documented in advance, adhered to in course design, and upheld in course delivery. The ability and willingness to do this meticulously and manage it effectively denotes the difference between a competent program and a world-class one.

We hope the combination of legacy, history, expertise, innovation and the student experience demonstrate how BU is building best practice in online PM education.

\section{References}

Casey, D.M. 2008, A journey to legitimacy: the historical development of distance education through technology, TechTrends: Linking Research \& Practice to Improve Learning, vol. 52, no. 2, 45-51.

Chaney, B.H., Eddy, J.M., Dorman, S.M., Glessner, L.L., Green, B.L. \& Lara-Alecio, R. 2009, A primer on quality indicators of distance education, Society for Public Health Education, vol. 10, no. 2, 222-231.

Cicmil S. \& Hodgson D. 2006, New possibilities for project management theory: a critical engagement, Project Management Journal, vol. 37, no. 3, 111-122.

McBrien, J.L., Cheng, R. \& Jones, P. 2009, Virtual spaces: employing a synchronous online classroom to facilitate student engagement in online learning, The International Review of Research in Open and Distance Learning, vol. 10, no. 3, accessed 07/07/2010, http://www.irrodl.org/index.php/irrodl/article/viewArticle/605

McLaughlin, C. \& Lee, M.J.W. 2008, The three P's of pedagogy for the networked society: personalization, participation, and productivity, International Journal of Teaching and Learning in Higher Education, vol. 20, no. $1,10-27$.

Phillips, P., Wells, J., Ice, P., Reagan, C. \& Kennedy, R. 2008, A case study of the relationship between socioepistemological teaching orientations and instructor perceptions of pedagogy in online environments, Electronic Journal for the Integration of Technology in Education, vol. 6, 3-27

Robinson, C. 2009, Lessons on learning, The Journal for Quality and Participation, vol. 32, no. 1, $25-27$.

Shelton, K. 2011, A review of paradigms for evaluating the quality of online education programs, Online Journal of Distance Learning Administration, vol. IV, no. I, Spring 2011, http://www.westga.edu/ distance/ojdla/spring141/shelton141.html

Shelton, K., \& Saltsman, G. 2004, The dotcom bust: a postmortem lesson for online education, Distance Learning, vol. 1 , no. $1,19-24$.

Sloan Consortium 2009, The 5 pillars, http://www.sloan-c.org/

Warburton, R.D.H., Leybourne, S. \& Kanabar, V. 2011, The 3rd decade of online education: what have we learned? Our Digital Renaissance conference, Florence, Italy, 10-12 November 2011.

Zlateva, T. 2011, Dimensions of course design and delivery and their effect on student satisfaction/perception in online learning, proceedings of the 7th Annual International CSECS Conference, 6-10 July 2011, Sofia/Dobriniste, Bulgaria. 
About the authors:

Dr Stephen A. Leybourne is a well known lecturer in organisational and human behavior, innovation, and project and change management. He has presented at conferences including the PMI ${ }^{\circledR}$ Research Conference and the Academy of Management; winning "best paper" awards from the Academy of Management in 2006 and from the International Management Development Association in 2009. He has been a leading manager for several international banking institutions and was the founding secretary of the Organizational Transformation, Change and Development Special Interest Group at the British Academy of Management. He has published in a variety of industry journals, and is an editorial board member of the Project Management Journal and of the Journal of Project, Program and Portfolio Management. He was an invited keynote speaker at the 5th Brazil National PM Conference in Brasilia in 2010.

Email: sleyb@bu.edu

Dr Vijay Kanabar, a recipient of several awards for outstanding teaching and research, is internationally recognised for his innovative work in project management and information technology. His contributions to the field of project management are utilised by practitioners in the industry today, and include designing the 4GT parametric project cost estimation model and developing a framework for project risk management. He has authored several books and has been invited to speak at numerous national conferences. He has had substantial business and consulting experience in several Fortune 500 corporations as well as other organisations worldwide, and has been recognised by the Wall Street Journal and other media.

Dr Roger D.H. Warburton directs the project management curriculum at Boston University's Metropolitan College. He has over twenty-five years of professional experience in manufacturing and high technology companies. Previously, as vice president of the Software Technology Division of Jaycor, he was the project manager for the technical analysis of information systems. In terms of research, he recently discovered exact theoretical solutions to the full set of supply chain equations, opening up a new range of information system research opportunities. He has also developed algorithms, heuristics and guidelines for supply chain management systems; developed a formal Quick Response Manufacturing (QRM) model to determine when outsourcing is competitive; and calculated the optimal ratio of domestic to outsourced manufacturing. 